\title{
A LEITURA LITERÁRIA NA EDUCAÇÃO INFANTIL: ANÁLISE DE NARRATIVAS ESCRITAS POR UMA PROFESSORA
}

\section{LITERARY READING IN CHILD EDUCATION: NARRATIVE ANALYSIS OF WRITTEN OF A TEACHER}

Ana Carolina Ferreri Martins ${ }^{1}$ Ana Maria Esteves Bortolanza ${ }^{2}$

\section{RESUMO}

O objetivo do artigo é analisar leitura literária na Educação Infantil em seus aspectos teóricos e práticos, por meio de narrativas escritas de uma professora. O estudo (2019-2020) foi elaborado por meio de uma pesquisa qualitativa, de caráter exploratório, tendo como procedimento duas narrativas escritas por uma professora de uma turma de 5 anos, em uma escola de Educação Infantil de Tubarão, SC. Explora questões práticas e teóricas sobre a leitura literária em atividades da criança com os objetos da escrita, especificamente, livros de literatura infantil. O artigo evidencia o distanciamento entre os aspectos teóricos da leitura literária em relação às práticas pedagógicas da professora participante da pesquisa. Conclui-se que é preciso, na Educação Infantil, organizar as condições para a vivência da criança com a leitura literária como espaço de partilhas e relações que possibilitem as interações das crianças com a leitura literária no cotidiano.

Palavras-chave: Educação Infantil; Leitura; Literatura Infantil.

\begin{abstract}
The aim of the article is to analyze theoretical and practical aspects of literary reading in Early Childhood Education through written narratives by a teacher. The study (2019-2020) was elaborated by means of a qualitative research of exploratory character, having as procedure two narratives written by a teacher of a class of 5 years, in a school of Infantile Education of Tubarão, SC. It explores practical and theoretical questions about literary reading in children's activities with the objects of writing, specifically, children's literature books. The article highlights the distance between the theoretical aspects of literary reading in relation to the pedagogical practices of the teacher participating in the research. We conclude that it is necessary, in Early Childhood Education, to organize the conditions for the child's experience with literary reading as a space for sharing and relationships that enable children's interactions with literary reading in daily life.

Keywords: Child education; Children's literature; Reading.

\footnotetext{
1 Graduação em Pedagogia, Universidade do Sul de Santa Catarina (UNISUL), email: anaferreri2505@hotmail.com, http://lattes.cnpq.br/3568863187414585, Orcid: https://orcid.org/0000-0001-7616-6363..

2 Doutora em Educação (UNESP), Pós-Doutoramento em Educação (Universidade de Évora, Portugal), Docente da Universidade do Sul de Santa Catarina (UNISUL), email: amebortolanza@uol.com.br, lattes.cnpq.br/1422415145212310, https://orcid.org/0000-00034608-2139.
} 


\section{INTRODUÇÃO}

O estudo realizado que resultou neste artigo se insere no campo da linguagem literária, especificamente, da leitura literária na Educação Infantil. Seu objetivo é analisar a leitura literária em seus aspectos teóricos e práticos, por meio de narrativas escritas por uma professora de crianças de 5 anos, de uma escola pública de Educação Infantil situada em Tubarão, SC.

O interesse pela temática vem de minha atuação em uma escola de Educação Infantil, particularmente, da observação de situações de leitura literária em uma turma de 5 anos de idade, em que eu trabalho como estagiária. A escolha da temática despertou em mim o desejo de compreender como essa atividade pode contribuir para a formação integral da criança, o que justifica a escolha do objeto de pesquisa.

Tendo como objeto a leitura literária, a questão de pesquisa que pretendemos responder é: Como a leitura literária se realiza na Educação Infantil, por meio do trabalho pedagógico de uma professora, com crianças de 5 anos de idade? Essa questão envolve analisarmos o acesso das crianças aos livros, a interação delas com a leitura literária, os critérios estabelecidos para a escolha dos livros, conteúdos, valores da leitura literária, concepções da professora sobre a temática, as situações de leitura, como a atividade de leitura literária é mediada, quais são os aspectos teóricos presentes nas narrativas da professora que dão sustentação às suas práticas pedagógicas.

Trata-se de uma pesquisa exploratória, de caráter qualitativo, segundo Minayo (1993), que busca uma aproximação com o tema pesquisado: a leitura literária na Educação Infantil. Definimos a pesquisa como qualitativa à medida que analisa os significados das narrativas da professora participante, suas ideias, opiniões e percepções sobre a temática leitura literária. Escolhemos a pesquisa qualitativa por ser um espaço de investigação de questões particulares do cotidiano escolar e seus significados.

A pesquisa qualitativa busca, portanto, os significados na realidade social do objeto pesquisado, e para isso,

[...] trabalha com o universo de significados, motivos, aspirações, crenças, valores e atitudes, o que corresponde a um espaço mais profundo das relações, dos processos e dos fenômenos que não podem ser reduzidos à operacionalização de variáveis. (MINAYO, 1993, p. 22).

A fundamentação teórica baseou-se nos estudos de Bortolanza e Freire (2018), Rodrigues e Bortolanza (2019), Bortolanza (2011), Bajard (2010), Colombo (2009), Fino (2011), Junqueira (2015), Mello (1999), Rodrigues (2019), Silva (2017) e outros autores. 
A pesquisa foi realizada por meio de duas narrativas escritas, a partir de roteiros planejados previamente para explorar a leitura literária, de forma a captar o olhar da professora sobre a temática. Sobre o instrumento de pesquisa empregado, a narrativa escrita, Lima, Geraldi e Geraldi (2015, p. 38) a definem como uma experiência que "[...] se funda na ética da responsabilidade, bem como em uma pretensão metodológica de aproximação entre o mundo vivido e o mundo da teoria". Justificamos a escolha da narrativa porque esse instrumento de pesquisa possibilita compreender a relação da professora com a leitura literária, o que pensa, como trabalha a literatura infantil.

Consideramos relevante o emprego das narrativas escritas para conhecer a prática pedagógica da professora em relação à leitura literária na Educação Infantil, sem deixar de lado os aspectos teóricos que envolvem essa temática. Enfim, o foco da análise dos dados é captar o olhar da professora, a partir de sua atuação docente no campo da leitura literária, de maneira a refletir aspectos teóricos e práticos à luz dos autores referenciados.

Fiorentini, ao tratar sobre o desenvolvimento profissional, mostra a importância da narrativa por se constituir como um instrumento de pesquisa que dá voz e vez aos docentes, ao afirmar que,

[...] para investigar os processos de constituição da (s) identidade (s) dos professores em comunidades investigativas, é necessário dar-lhes voz e vez. Uma possibilidade para isso tem sido a análise de materiais escritos pelos próprios professores..., em que os professores tomam seu desenvolvimento profissional e sua aprendizagem docente como eixos analíticos. (2013, p. 19).

A opção metodológica pela narrativa como instrumento de pesquisa também proporcionou uma situação em que a professora pode descrever suas experiências pedagógicas com a leitura literária, possibilitando uma possível reflexão de sua própria prática docente sobre essa temática.

Isto posto, estruturamos o artigo em três tópicos, além da introdução, considerações finais e referências. O primeiro tópico trata dos aspectos teóricos da temática leitura literária elaborados por meio da leitura dos autores pesquisados, enquanto o segundo tópico aborda questões conceituais sobre a literatura infantil na Educação Infantil, também resultado das leituras de autores que tratam da literatura para crianças. No terceiro tópico, analisamos os dados coletados nas duas narrativas escritas pela professora, que devem responder aos objetivos propostos em relação aos aspectos teóricos e práticos da leitura literária na Educação Infantil.

Situamos inicialmente a escola de Educação Infantil como espaço educativo em que a criança precisa, acima de tudo, se sentir segura e emocionalmente estável para se motivar e se envolver em aprendizagens significativas, que valorize suas opiniões e a estimule para 
participar ativamente no cotidiano escolar. A sua plena integração no grupo de crianças, a construção da sua autoestima, o respeito pelas opiniões alheias e a aceitação das diferenças constituem os alicerces de uma educação para a formação integral. Nesse sentido, e não sendo a única via para atingir esse fim, a literatura para a infância é um precioso meio para o desenvolvimento integral da criança e, em particular, da linguagem, da imaginação e do pensamento.

Tendo em vista a importância de organizar o espaço da escola, trazemos Carvalho e Rubiano (2000, p. 117) que tratam a respeito da influência do ambiente na educação das crianças, mostrando que [...] “... os comportamentos infantis são influenciados pelo ambiente fornecido pelos adultos de acordo com seus objetivos pessoais, construídos com base em suas expectativas culturais relativas aos comportamentos e desenvolvimento infantis".

Assim sendo, o espaço educativo deve ser planejado e voltado às necessidades da criança, desde os primeiros anos de vida como sujeitos de direitos, especificamente, do direito à infância.

\begin{abstract}
Pensar a educação infantil como espaço acolhedor de emancipação exige a recusa das práticas reguladoras, homogêneas, universalizantes e impessoais. Para tanto, fazse necessário buscar nas crianças, nas suas práticas, nos seus modos de ser, a possibilidade da construção de novos tempos e espaços em que elas sejam respeitadas como crianças e possam viver como crianças. Não queremos uma educação que prepare para a emancipação, queremos que as crianças vivam a condição de sujeitos de direitos e principalmente o direito de aprender a ser criança e viver intensamente essa experiência. (BATISTA, 1998, p. 54).
\end{abstract}

Organizar o ambiente adequadamente para que a criança tenha contato com a leitura, o livro, a literatura contribui para sua formação, no sentido ser capaz de imaginar, pensar e sentir com autonomia em sua relação ao outro, tanto no ambiente escolar e familiar como na sociedade. O professor é o responsável pela organização do ambiente adequado à leitura literária. Como organizador do espaço educativo e mediador das situações de leitura com a criança, cabe a ele proporcionar o acesso aos livros e outros suportes de leitura e à literatura infantil, mediar esses conhecimentos, criar na criança o desejo de apropriar-se da leitura e o gosto de ler.

Isto posto, partimos do pressuposto que o trabalho pedagógico organizado pelo professor com as diferentes linguagens possibilita o desenvolvimento da criatividade e da imaginação, e de outras funções psicológicas da criança, formando assim sua personalidade, inteligência e consciência. (MELLO,1999). 


\section{A leitura na educação infantil: alguns aspectos teóricos}

A arte literária, em diferentes linguagens, visa a formação integral da criança com formas, cores, movimentos e palavras etc. Nesse sentido, os textos literários podem ampliar a visão de mundo da criança, de maneira que ela se desenvolva como indivíduo autônomo que pensa, sente e age na sociedade.

Para Barbosa (2009), a linguagem implica a possibilidade de construir significados, por isso exerce a função de comunicação, de expressão e de transmissão de saberes, envolvendo o compartilhamento dos sentidos produzidos em diferentes formas de expressão, ações corporais, visuais, gestuais, linguageiras, nas relações interpessoais da criança.

$\mathrm{Na}$ escola, a linguagem verbal vem sendo trabalhada, por um longo tempo, como uma área de conhecimento voltada apenas para o ensino da língua portuguesa. Hoje, ainda que parcialmente, é socialmente empregada para indicar diferentes formas de manifestações culturais, científicas da cotidianidade, vista sob a ótica dos gêneros textuais em variados usos e funções. Portanto, são vários os campos de conhecimento que se servem da linguagem como ferramenta de organização de sistemas de signos, como algo com um significado, o gesto, os movimentos corporais, faciais, as imagens, as palavras, enfim, todas as formas possíveis de linguagem verbal e não verbal.

Neste sentido, as linguagens são saberes da ação: simbólicos, expressivos, científicos, artísticos e tecnológicos que demonstram a capacidade humana para falar, escrever, manipular, expressar e produzir um número ilimitado de pensamentos e experiências independentemente do conhecimento formal das disciplinas sistematizadas, hierarquizadas e lineares. (BARBOSA, 2009, p. 84-85).

Quanto ao conceito de leitura, reafirmamos as ideias de Kleiman (1989) e Orlandi (1988) citadas por Bortolanza e Freire (2018, p. 135):

[...] a leitura é um processo interativo, construído nas relações sócio-históricas e culturais, portanto é um processo em que o leitor constrói ativamente os significados de um texto em uma determinada situação, partindo dos objetivos propostos, de seu conhecimento prévio que pressupõe conhecimentos de mundo, linguísticos e textuais.

Ler é um ato de apropriação da cultura, construída de geração em geração pelos homens, assim as práticas de leitura literária como práticas sociais fazem parte do mundo da cultura. Para assimilar as práticas sociais de leitura, a criança interage no meio em que vive, nas relações com a família, com os amigos, e na escola de Educação Infantil. Ao interagir 
com os textos literários, nos diálogos com a professora e as outras crianças, a criança forma sua atitude como pequeno leitor. Nesse sentido, é indispensável que se organize as condições para as experiências das crianças com os livros e outros suportes como revistas, vídeos, filmes, nos quais se apoiam os textos literários.

Fundamentadas em Larrosa (2001), Bortolanza e Freire (2018, p. 137) abordam a leitura como uma experiência que

[...] mostra a transformação do seu olhar e experimenta o mundo de outra forma". A experiência da leitura ensina, portanto, olhar o mundo e as letras dialeticamente, isso implica uma postura de leitor que, reconhecendo-se como sujeito-histórico, dialogue com o texto transformando-o através de sua leitura e sendo por ele transformado.

Entendemos que o ato de ler proporciona à criança situações para assimilar os conhecimentos de mundo, apropriando-os à medida que experimenta e se expressa pelas diferentes linguagens. Nessa direção, a criança constitui-se humanamente, transforma-se pela leitura e é transformada por ela.

A apropriação das práticas de leitura pela criança, possibilita o desenvolvimento de distintas habilidades, capacidades e aptidões, aumenta seu vocabulário e funções psicológicas fundamentais como a imaginação, o pensamento, a atenção etc.

Fino (2001), fundamentado em Vigotski, conceitua a linguagem como um instrumento constituído de signos que viabiliza a comunicação e, também, desenvolve o pensamento. Nesse sentido, a linguagem medeia a relação do indivíduo com o outro, e nesse processo a criança se constitui como ser histórico-cultural. A linguagem literária é necessária para o desenvolvimento da imaginação da criança. Junqueira (2015) baseada nos estudos de Vigotski mostra que a experiência da criança quanto mais rica mais desenvolve sua imaginação. É tarefa do professor organizar as condições para trabalhar a atividade criadora da criança na Educação Infantil, de maneira trazer para a escola da infância a variedade de textos literários.

Arena (2010), autor em que Bortolanza e Freire (2018, p. 141) se apoiam para conceituar literatura, explicam que o texto literário é um objeto mediador da criança ao entrar em contato "com a cultura de sua época, mas [que] transcende a ela, tanto para o passado, quanto para o futuro". Reiteramos os autores, pois a leitura conduz o leitor a diferentes lugares, tempos e espaços, visto que ao ler a criança se transporta para um mundo de possibilidades e de histórias, que podem ser vividas e revividas por ela, inclusive histórias em que ela projeta o tempo futuro. Nas situações de leitura literária, a criança imagina, fantasia e cria, esse processo de criação é crucial para seu desenvolvimento. 
Mello mostra que entre outras, as aptidões para ler e escrever são aprendidas pela criança, destacando que o processo de aprendizagem é que impulsiona seu desenvolvimento e não o contrário.

É o aprendizado que possibilita o despertar da capacidade de perceber as cores, as formas, os sons, a capacidade de falar, de pensar, de raciocinar, de lembrar, de emocionar-se, de amar, a aptidão para a leitura, para a escrita, para a ciência, para a arte, etc.” (MELLO, 1999, p. 19).

A criança que, desde muito cedo, tem a oportunidade de conviver com as histórias e outros tipos de textos, forma ideias e atitudes sobre o que lê, desenvolve seu comportamento leitor, e assim se forma o pequeno leitor. À vista disso, o trabalho pedagógico com textos literários de boa qualidade é imprescindível ao favorecer o relacionamento da criança com os livros e com outros suportes do texto literário. Mesmo de ser alfabetizada, a criança pode formar a atitude leitora, e mais tarde adquire o hábito de ler. Outro aspecto importante da leitura está no desdobramento de repertório de seu vocabulário, no desenvolvimento de frases simples que se tornam mais complexas, dando-lhe condições cada vez mais de empregar a linguagem para conhecer o mundo e, ao mesmo tempo, formar sua personalidade, inteligência e consciência. (MUKHINA, 1996).

Apreendemos com Mello (1999) que o ato de ler amplia as referências da criança de maneira a colaborar para seu desenvolvimento integral, de todas as capacidades, entre elas, de pensar e agir com autonomia no meio do qual faz parte. Como fonte de aprendizado, a leitura é também uma experiência de entretenimento em seus aspectos lúdicos, pois, brincando, a criança se coloca como sujeito num lugar de relação no mundo dos adultos. A leitura é, ainda, um objeto que cria condições de a criança explorar as primeiras palavras escritas e descobrir a linguagem escrita em sua complexidade.

Reconhecemos, nessa perspectiva, que as habilidades, aptidões e capacidades que a criança desenvolve na infância são levadas para a vida adulta, por isso cultivar uma relação com a leitura que faça sentido para ela, é essencial para sua formação integral. Não se trata de aprender a ler e escrever no sentido de alfabetizar a criança precocemente, deixando de lado o mais importante e necessário, seu mergulho na cultura escrita para conhecer os usos e as funções sociais da leitura e da escrita em textos diversos.

Trazemos Foucambert (2008) citado por Rodrigues e Bortolanza (2019, p. 114) que nos alertam para a necessária distinção entre a alfabetização precoce e o trabalho professor com a leitura como recurso funcional. Para o autor "[...], é suficiente permitir à criança viver na escola, desde bem pequena, situações naturais de leitura, isto é, situações que não sejam artificialmente amputadas do recurso à escrita”, pois a escrita não pode ser introduzida na vida 
escolar da criança forçosamente, "basta não excluí-la sob o pretexto duplo de que a criança não pode utilizá-la [...]".

Por meio do ato de ler, a criança experimenta outros pontos de vista expressos pelos colegas da turma e do professor, que compartilham com ela distintos valores, fatos, atitudes etc. Para a leitura ter sentido para a criança, deve partir de uma necessidade de ela descobrir o mundo, descobrir a escrita como representação da realidade. Mello chama a atenção para o equívoco de ensinar a ler e a escrever como um fim em si mesmos, o quê frequentemente, acontece na escola, tanto na Educação Infantil como no Ensino Fundamental.

[...] ler apenas para aprender a ler e escrever apenas para aprender a escrever configuram-se como fazeres que podem fazer sentido para o adulto que ensina, mas não para a criança que está sendo introduzida no mundo da escrita. (MELLO, 1999, p 22).

É preciso também definir o papel de mediação pedagógica da professora na Educação Infantil. De acordo com Silva (2017), esse papel é incentivar a relação da criança com o livro e outros suportes da escrita, tendo em vista que um dos motivos, o mais importante deles, é o desenvolvimento pleno da personalidade infantil. Nessa direção, a professora pode elaborar projetos de leitura com o objetivo de formação dos pequenos leitores, como parte da educação estética da criança. A escola de Educação Infantil também é um espaço para a vivência da criança em situações comunicativas pelas quais ela forma o comportamento leitor, alicerce para sua formação de leitura e do hábito de ler.

Reconhecemos com Silva (2017), que o educador de Educação Infantil é aquele que educa a criança para viver em sociedade, como um sujeito ativo, crítico e autônomo. Nesse sentido, a prática da leitura literária pode contribuir, pois o contato precoce da criança com a literatura para a infância, além de todos os benefícios que acarreta, é de extrema importância para lhe dar segurança e bem-estar necessários à sua participação na sociedade.

Silva (2017, p.181) recorre à Gusmão-Garcia e Silva (2000) para explicar o sentido de experiência de leitura para a criança, sua influência na formação de sua personalidade e na relação que possibilita a ela estabelecer no seu entorno.

Propiciar a oportunidade da experiência "leitora" - no sentido mais amplo que essa palavra possa ter - é não apenas despertar o gosto da criança/aluno pela leitura, mas também desenvolver a consciência da realidade à sua volta. Como afirmam Gusmão-Garcia e Silva (2000), o contato, desde muito cedo, com o livro, revela-se fundamental para a formação de "indivíduos questionadores e capazes de posicionar-se conscientemente diante da realidade e inserir-se no contexto de uma sociedade mais moderna" (p. 21), por mais cedo que esse contato se efetive.

Na escola de Educação Infantil, desde os primeiros anos de vida, a criança manuseia, explora, brinca, escuta histórias e poesias, e assim desenvolve a capacidade de criar, de 
fantasiar, de imaginar e se apropriar da cultura escrita. A fim de que a leitura literária cumpra seu papel no desenvolvimento da criança, a instituição de Educação Infantil precisar organizar-se como espaço de partilhas e relações entre as crianças e os adultos, ampliando as experiências vividas fora da escola, com as famílias, amigos, vizinhos e outros. É na escola da infância que as crianças, em interações com outras crianças, adultos e objetos, ampliam seus conhecimentos de mundo e suas experiências.

\section{A literatura na educação infantil: questões conceituais}

Como gênero literário, a literatura infantil é relativamente um gênero novo no mundo ocidental, tendo seu início já no final do século XVII, com Charles Perrault e seus contos. No Brasil, a literatura para crianças data do final do século XIX e começo do século XX. Conforme Zilberman e Lajolo (2007) citadas por Ribeiro (2018), os textos literários eram traduções e adaptações da literatura estrangeira.

A literatura infantil representa para Zilberman (1985), mencionada por Ribeiro (2018), um meio essencial para sintetizar a realidade no tempo e no espaço em que o texto literário é produzido, permanece e se comunica em qualquer época, ao abordar o drama da vida humana em seu caráter de universalidade. O caráter de universalidade presente no texto literário é fundamental para o processo de constituição humana da criança.

A literatura infantil como bem cultural cria as condições para o desenvolvimento da criança em seu processo de humanização. Na perspectiva histórico-cultural, a criança tem acesso à cultura produzida pela humanidade por meio da educação como processo de humanização. Ela se apropria das qualidades humanas que estão postas nos objetos e fenômenos, que precisam ser mediadas por uma pessoa mais experiente para que ela se aproprie e se desenvolva plenamente. Nesse processo, a criança também produz cultura.

Desde seu surgimento, a literatura infantil caracterizou-se por uma forma de ensinamento dirigido à criança, e só mais tarde foi considerada expressão artística na escola, colocando em cena o prazer de ler da criança como pequena leitora em formação. A herança histórica que temos hoje é da literatura infantil como instrumento de dominação na sociedade de classes, segundo Colombo (2009, p. 50) baseando-se em Perrotti (1986, p.16).

[...] a literatura para crianças e jovens apresentou-se quase sempre munida de um discurso que visava em primeiro lugar a atuar junto ao leitor, no sentido de integrálo à ordem social dominante. Não se tratava, portanto, de mero processo de assimilação social, mas de um discurso classista, identificado com as forças sociais dominantes. 
Como instrumento de dominação, a literatura tinha a finalidade de integrar a criança à sociedade para exercer certo controle no ensino de certos valores de cidadania. Nessa perspectiva, a literatura infantil historicamente esteve muito ligada ao universo pedagógico, inicialmente pensada como instrumento de ensino da leitura, tinha como finalidade a alfabetização. Essa característica não foi favorável às práticas pedagógicas com o texto literário, pois deixou-se de lado muitas vezes seu caráter estético.

Embora, a literatura infantil tenha se caracterizado desde seu surgimento como uma literatura escolarizada, contrapondo-se ao lúdico e à fruição do texto literário, outra característica se faz presente na literatura infantil, a fantasia que a categoriza como uma atividade criadora. À vista disso, outros fatores também influenciaram a constituição da literatura infantil, como a fantasia produzida pela imaginação, presente nos clássicos de literatura infantil: Andersen, Perrault e irmãos Grimm, compilados da tradição oral.

A respeito do texto literário e suas particularidades, Cademartori (1987) é reiterada por Colombo que conceitua a obra literária como um recorte do mundo real que o transforma,

[...] sintetiza-o através do ponto de vista do narrador ou do poeta. Sendo assim manifesta, através do fictício e da fantasia, um saber, sobre o mundo e oferece ao leitor um padrão para interpretá-lo. Veículo do patrimônio cultural da humanidade, a literatura se caracteriza, a cada obra, pela proposição de novos conceitos que provocam uma subversão do já estabelecido. $(2009,49)$.

A respeito das particularidades do texto literário, o texto literário reconfigura o real, visto pela ótica do autor/narrador ao criar um mundo de fantasia que transforma a realidade e cria novos mundos.

Ribeiro (2018, p. 22)) retoma Coelho (2000) ao explicar o papel da literatura infantil “como objeto que provoca emoções, dá prazer ou diverte e, acima de tudo, modifica a consciência de mundo de seu leitor, a literatura infantil é arte". Concordamos que a literatura infantil colabora para formar o pequeno leitor por meio do ato de ler que emociona, entretém e deleita de maneira a emancipar criança, dado seu caráter estético e universal, fonte de prazer no ato de ler, também pela possibilidade de experiências da criança com a linguagem literária que constituem sua personalidade. Portanto, o papel preponderante da literatura infantil, como objeto cultural e artístico em suas formas mais complexas, é contribuir para a formação da criança. Por meio da literatura infantil, a criança torna-se sujeito de linguagem.

Como manifestação cultural rica e complexa, o texto literário é um produto cultural apropriado pela criança que nele mergulha para adentrar ao mundo da cultura. É também uma rica experiência para a criança, leitora em formação, nos primeiros contatos com o livro e com a leitura literária, pois a coloca numa relação dialógica com outras vozes - os autores dos 
textos, as crianças, a professora e consigo mesma -, o que contribui para sua compreensão da realidade circundante. (RIBEIRO, 2018).

Afirma Ribeiro (2018), baseando-se em autores como Abramovich (1997), Coelho (2000), Colomer (2003), Arena (2010), Cademartori (2010), Burlamarque, Martins e Araújo (2011), Souza, Corrêa e Vinhal (2011), Brocanelli, Girotto e Andrade (2013), que o texto literário é um instrumento para a criança conhecer lugares reais e imaginários, imaginar e fruir o texto, estendendo seus conhecimentos de mundo, horizontes cognitivos e emocionais, ao vivenciar situações em outros tempos, espaços e contextos.

Ribeiro (2018) traz Arena (2010) em dois aspectos para abordar o texto literário. O primeiro aspecto explica como o texto literário medeia a relação da criança com a cultura na qual ela está inserida abrindo a possibilidade de ela se deslocar para o passado e o futuro. $\mathrm{O}$ segundo aspecto mostra como a criança necessita do mergulho na cultura para ter acesso ao gênero literário em seus usos e funções, como o conto, a poesia, a fábula e outros. É dessa maneira que a criança se apropria da materialidade do livro como objeto cultural palpável, que ela pode pegar, manusear, explorar, brincar e descobrir no texto literário ideias, imagens, signos escritos, significados. Em ambas as situações, a criança como ser histórico apropria-se do texto literário e é capaz de significar a realidade por meio dele, atribuindo sentidos nesse processo que chamamos de leitura literária.

Outro aspecto da leitura literária discutido por Lajolo (1995), e citado por Ribeiro (2018) é a falta de autonomia do educador, sua formação inconsistente, de modo a reduzir a literatura a situações de leitura escolar em simples ações mecânicas. Falta-lhe, na maioria das vezes, os fundamentos teóricos necessários para trabalhar com as crianças esse objeto de ensino. Isso se reflete no acervo literário da escola, no planejamento do educador, na execução de atividades que criem as condições necessárias ao desenvolvimento das capacidades especificamente humanas nas crianças.

Uma outra questão fundamental a ser dimensionada é o papel dos livros de literatura infantil, geralmente, produzidos com texto e imagem ou apenas imagem, e a forma como vêm sendo oferecidos às crianças, sem a exploração adequada na mediação pedagógica. Bajard (2007), citado por Ribeiro (2018, p. 127-128), esclarece o papel central do livro com imagem para a criança, explicando que "[...] as imagens impedem a fuga do olhar para longe da narrativa gráfica. Elas o cativam, antes, durante ou depois da transmissão vocal, que, por si mesmo, não exaure mais a fonte de prazer que constitui o livro".

Ainda uma questão importante levantada no estudo refere-se à prática pedagógica do educador que precisa "dessacralizar" o texto literário. Zilberman (1985), reiterada por Ribeiro (2018) que argumenta a necessidade de o livro de literatura para crianças favorecer suas 
vivências literárias em situações de leitura, desmistificando-o como objeto sagrado que, muitas vezes, nem pode ser tocado pela criança na escola. Isso requer repensar como os livros chegam às mãos da criança, quantos chegam, com que qualidade, como são apresentados e mediados pelo professor, como a criança interage com eles.

À vista disso, apontamos alguns critérios enunciados por Ribeiro (2018) aos professores de Educação Infantil para a realização de leituras literárias e contação de histórias às crianças. Segundo a autora, faz-se necessário garantir o acesso à variedade de livros de literatura infantil, organizar os espaços onde ocorrem as situações de leitura literária, exercer o papel mediador ao ler para/com a criança, observar o comportamento da criança na escuta de histórias e aguçar suas percepções em situações de leitura literária.

A professora Maria Clara ${ }^{1}, 26$ anos, 4 anos de atuação na Educação Infantil, trabalha em uma escola de Educação Infantil da Rede Municipal de Ensino de Tubarão - SC, com uma turma pré I, com 21 crianças de 5 anos de idade. De acordo com a professora, "as crianças são calmas e sempre dispostas a aprenderem mais sobre o que é proposto". (Maria Clara, $30 / 03 / 2020)$.

\section{Análise da primeira narrativa da professora}

Ao solicitar à professora participante do estudo a escrita da primeira narrativa, enviamos um roteiro. Explicamos o objetivo da pesquisa: analisar a leitura literária na Educação Infantil por meio do olhar de uma professora de uma turma de 5 anos, em seus aspectos teóricos e práticos. A narrativa como instrumento de pesquisa possibilita o relato das experiências vividas, por isso optamos pela escrita de suas experiências com a leitura literária e as crianças, no cotidiano da escola da infância.

A professora iniciou escrevendo sobre o livro didático, disponibilizado pela Secretaria de Educação do município, e situou a temática leitura literária no contexto do planejamento e do uso do livro didático. À título de informação, o livro didático adotado é o Pé de brincadeira, de Angela Cordi, distribuído pelo PNLD - Plano Nacional do Livro Didático para a Educação Infantil, em 2019.

A professora inicia sua narrativa discorrendo sobre o planejamento e o livro didático adotado.

O planejamento das atividades acontece quinzenalmente. O município, a algum tempo, disponibilizou aos professores um livro pedagógico didático em que contém diversos tipos de atividades, objetivos e práticas a serem trabalhadas com as crianças. Dentro do mesmo, a todo momento, são percebidas práticas que envolvem a literatura e a leitura literária. (Maria Clara, 30/03/20).

\footnotetext{
${ }^{1}$ Maria Clara é o nome fictício escolhido pela professora participante da pesquisa para preservar sua identidade.
} 
Segundo o Guia Digital PLND (BRASIL, 2019), o livro de Pé de Brincadeira, de Angela Cordi, destina-se a crianças de 4 e 5 anos, na Educação Infantil, e foi elaborado de acordo com a Base Nacional Comum Curricular (BNCC), leis e princípios fundantes da Educação Infantil, a nível nacional. Na apresentação, afirma-se a defesa aos direitos de aprendizagem, tendo em vista o desenvolvimento para a criança, e reafirma-se a infância como categoria social historicamente construída, articulando essa concepção com as instituições família e escola. Contudo, questionamos a adoção do livro por entender que o foco é na ação docente como aquele que domina o conhecimento, enquanto a criança fica secundarizada, na função de receptora dos conteúdos didáticos, o que pode inviabilizar o desenvolvimento de suas potencialidades.

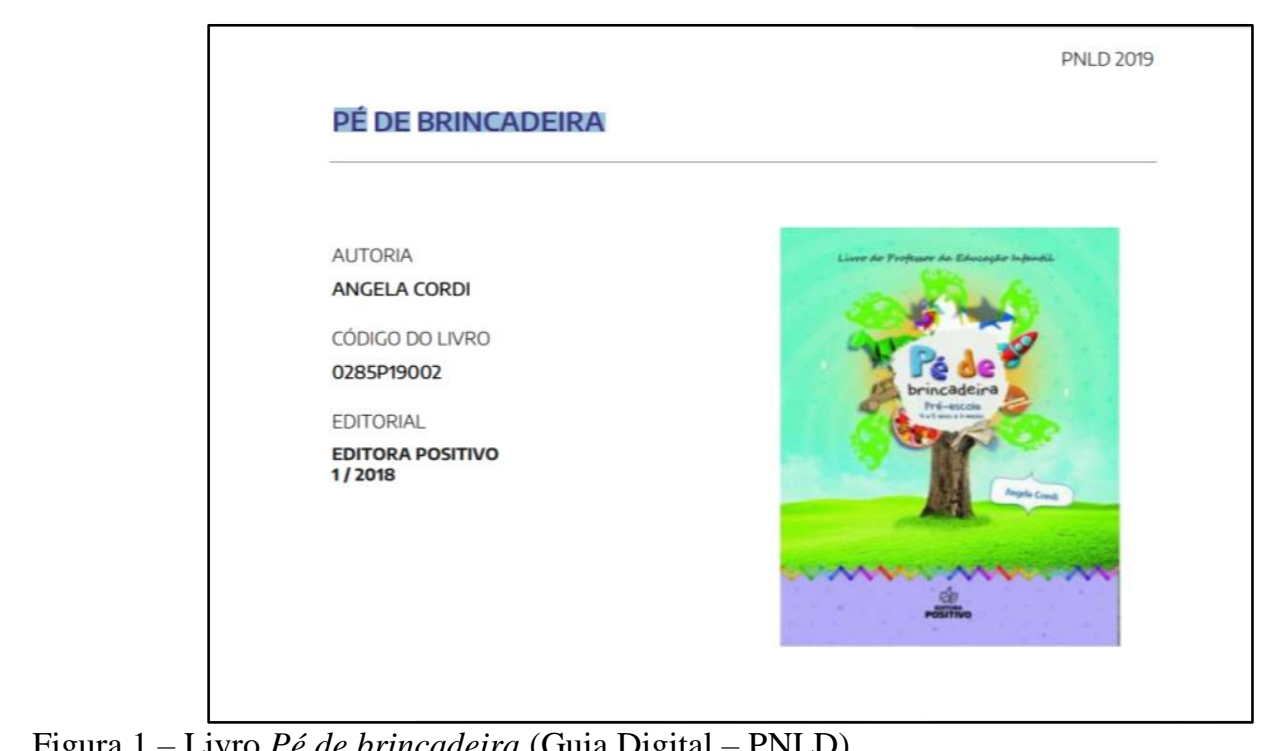

Figura 1 - Livro Pé de brincadeira (Guia Digital - PNLD)

Fonte: http://www.editorapositivo.com.br/flipbooks/PNLD/pe-de-brincadeira.

Em relação ao trabalho pedagógico com o livro didático, a professora registra que,

O livro literário é sempre escolhido e selecionado dentro da temática que está sendo trabalhada. Ao finalizarmos a contação, em seguida sempre é aberto um momento para o diálogo, onde as crianças podem expor o que acharam sobre o livro, suas percepções, suas emoções, entre outros. Logo após, selecionamos duas ou três crianças para recontar a história a seus colegas. Sendo assim, ao termino cada criança pode pegar o livro em suas mãos, manuseando o mesmo. Neste momento as crianças ficam muito felizes e empolgadas. (Maria Clara, 30/03/20).

Podemos constatar que a professora explora o livro literário pela contação de histórias, depois ela solicita a duas crianças que recontem o que ouviram. Essas atividades situam-se na modalidade da linguagem oral. Embora imprescindíveis, faz-necessário alternar a contação com a leitura de histórias que possibilita à criança familiarizar-se com a linguagem escrita pela escuta do texto escrito. 
Há, de acordo com Bajard (2010), uma diferença entre a criança ouvir uma história contada e ouvir a mesma história lida pela professora, na primeira situação temos a contação da história para a criança, portanto no nível da oralidade. Na segunda situação, temos a leitura de uma história pela professora, no nível da escrita. Contar uma história é diferente de ler uma história para a criança. Na Educação Infantil, é imprescindível que a criança vivencie as duas situações para ter contato não só com a oralidade, também, com a escrita pela voz da professora.

\begin{abstract}
Na sala em questão, está sendo montado um espaço de leitura para as crianças, já disponibilizando em algumas caixas livros literários. Quando chegamos na sala com os livros, as crianças ficaram encantadas e queriam vê-los a todo momento. Com o passar do tempo esse interesse ainda surgia cada vez mais forte. Então, decidimos montar um espaço para que elas se acomodem para lerem um bom livro. Enquanto este espaço ainda não está terminado por falta de alguns recursos, as crianças têm o livre arbítrio de sempre, quando quiserem, irem até a caixa de livros para retirar um. Esta atitude é vista pela maioria das crianças, sendo que algumas já tem os seus livros favoritos. (Maria Clara, 30/03/20).
\end{abstract}

O fragmento acima relata a situação em que a professora Maria Clara registra quão importante é a autonomia da criança para escolher os livros que deseja folhear. Ler, ainda que não alfabetizada, é uma maneira de a criança criar a necessidade de ler. Um espaço de leitura agradável e acolhedor, seja uma biblioteca escolar ou um cantinho da leitura na sala, faz com que a criança se sinta acolhida e à vontade para interagir com o livro, mergulhando no mundo da escrita literária.

Furtado e Oliveira, 2011. p. 76) reiteram Petit (2008) que sugere ser a biblioteca escolar

[...] o principal caminho de interação entre os leitores e destes com a literatura, tanto em texto impresso como no mundo digital, e fazer a convergência entre essas pessoas e linguagens. Partilhar leituras deve ser encarado como uma maneira de incentivar a prática da mesma. A biblioteca tem vocação para ser o local da linguagem compartilhada (PETIT, 2008).

Outro dado que trazemos para análise da leitura literária, na Educação Infantil, é a abordagem da professora Maria Clara sobre o texto literário $O$ dia em que o monstro veio à escola, com o objetivo de trabalhar os "bons comportamentos" e os "maus comportamentos" da criança.

Um planejamento composto no início do ano, por exemplo, foi sobre os monstrinhos do comportamento. Sempre em roda, com a nossa música inicial começamos a contação de histórias. $O$ livro se chama "O dia em que o monstro veio à escola". As crianças amaram este momento, podemos conversas sobre o que o livro discutia, onde os mesmos iam falando. Em seguida cada criança pode pegar o livro em mão e manuseá-lo. Logo após, montamos um cartaz sobre o livro, separando assim um para os maus comportamentos e outro para os bons comportamentos. Cada criança ganhou uma gravura, ao identificar o que a mesma representava, a criança ia até o cartaz e colava na parte dos bons comportamentos ou maus comportamentos. As mesmas amaram a dinâmica, isso fez com que elas se apropriassem da leitura feita, de forma a colocar um significado no que foi confeccionado por elas. (Maria Clara, 30/03/20). 
A utilização do texto literário pela professora para trabalhar o comportamento das crianças revela a função utilitária atribuída ao texto literário que o torna pretexto para ensinar bons e maus comportamentos, fazendo com que os aspectos literários sejam substituídos por ensinamentos, e assim fica à margem o caráter estético do texto literário. Embora, a professora evidencie sua preocupação em possibilitar à criança o contato com o livro literário, como podemos constatar no trecho que se segue.

Acredito de desde muito pequena a criança deve ter contato com o mundo literário. Ao entrar nesse universo imenso de conhecimentos e aprendizagens, 5 a criança desde muito cedo passa a ter contato com a linguagem oral e também a linguagem escrita. (Maria Clara, 30/03/20).

A redução do texto literário a pretexto para trabalhar comportamentos resulta da escolarização da literatura infantil que,

[...] estreita relação entre o livro literário e a educação, chegando à criança uma literatura pedagógica como forma de reforçar ensinamentos escolares. Com uma função essencialmente utilitária, esse acervo muitas vezes usa o poder mágico da palavra para transmitir a experiência já vivida pelo adulto. Assim, as narrativas e mesmo as formas poéticas possuem um viés adultocêntrico. (RAMOS; PANOZZO, 2015, p. 75).

A função utilitária ainda está muito presente na escola, isso tem dificultado o encontro das crianças com o texto literário que perde sua essência: sua esteticidade.

\section{Análise da segunda narrativa da professora}

Na segunda narrativa, elaborada pela professora, algumas questões específicas foram solicitadas para que ela relatasse mais detalhadamente: os critérios de escolha dos textos literários, os livros trabalhados com as crianças neste ano, as temáticas, justificativa, a descrição de uma atividade, as contribuições das atividades de linguagem oral e linguagem escrita com os textos literários e, por fim, as linguagens trabalhadas com as crianças para que situássemos na temática do estudo.

A professora inicia seu relato identificando a fonte dos textos literários oferecidos às crianças: o livro didático, o acervo da escola e a Internet.

\footnotetext{
Os textos literários escolhidos para as crianças do pré alguns já vem como sugestão no livro do professor. Caso estamos dentro de um tema e o livro didático não propõe nenhuma sugestão, buscamos no nosso acervo de livros no CEI ou na internet, ressaltando que ele deve se encaixar na temática que está sendo trabalhada. (Maria Clara, 15/04/20).
}

Entendemos que a literatura para criança tem determinadas peculiaridades, e, nesse sentido, é preciso critérios para a escolha de textos literários para a criança em termos da 
materialidade do texto em seus aspectos formais e gráficos e, sobretudo a literariedade, os aspectos linguísticos do texto, os valores universais, que na relação texto-leitor possibilitam a interação da criança com literatura infantil.

Algumas das temáticas escolhidas foram sobre a identificação pessoal, identificação familiar, diversidade cultural, entre outras. Essas temáticas são sugeridas pelo livro didático do professor, onde seguimos com as temáticas "Toc-toc- bem-vindo a educação infantil" e "Eu, você e todos nós". (Maria Clara, 15/04/20).

Vigotski (2009) citado por Junqueira (2015, p. 23) explica que a capacidade de criação humana está diretamente relacionada às experiências vivenciadas "quanto mais a criança viu, ouviu e vivenciou, mas ela sabe e assimilou; [...] mais significativa e produtiva será a atividade de sua imaginação".

Ao comentar sobre o livro Todd Parr, constatamos novamente a preocupação da professora em trabalhar ensinamentos, deixando de lado o foco da leitura do texto literário que é sua literariedade.

O livro da família, de Todd Parr, por exemplo, trabalhamos sobre a importância da família, principalmente agora neste período de pandemia do covid-19. As crianças fizeram atividades que envolveram a família, como dobraduras de casa, desenho da família em palito de picolé, participação da família nas atividades, como produzir massinha de modelar. (Maria Clara, 15/04/20).

Embora o envolvimento da família nas atividades das crianças possa aproximar pais, filhos e a escola da infância, promovendo a interação necessária para a educação dos pequenos, a questão que se destaca no trecho relatado pela professora é a utilização do texto literário para outras finalidades, o que reafirma a predominância do caráter utilitário dado ao texto literário.

Bortolanza (2011, p. 3) retoma Perrotti (1986) para situar o discurso utilitário na literatura para crianças, que se baseia nos princípios da "moralidade e do pudor, da obediência e da ordem estabelecida", e cita "vários teóricos, afirmando que a linguagem da arte possui seus próprios caminhos, muito diferentes da doutrinação e da catequização do discurso utilitário".

Já no fragmento da narrativa da professora que se segue identificamos a preocupação em preservar o caráter estético dos textos literários, ao comentar sobre livros em sua diversidade cultural.

Os livros "Cada um com seu jeito, cada jeito é um" de Lucimar Rosa Dias e "O cabelo de Lelê", de Valéria Belém, nos falam sobre a diversidade cultural, onde a contação de histórias se faz. lúdica e proporciona as crianças esse leque de experiências. Procuramos fazer registros das crianças com adereços para montarmos um grande livro da turma, ressaltando a diversidade, confeccionamos bonecos cujo cabelo fosse folhas de árvore, entre outros. (Maria Clara, 15/04/20). 
Para Faria (2004), o professor deve conhecer uma vasta gama de livros de literatura infantil de modo a conhecer esse universo, os diferentes estilos, de projetos gráficos, de gêneros literários, etc., para não limitar seu trabalho apenas a textos narrativos, mas contemple uma gama variada de textos desde poéticos, narrativos, incluindo contos, fábulas, parlendas, dentre outros.

Ao analisar a qualidade dos livros literários para crianças, o professor pode "[...] decidir sobre os elementos literários que sejam úteis para ampliar o conhecimento espontâneo que a criança já traz de sua pequena experiência de vida”. (FARIA, 2004, p.21).

\begin{abstract}
A linguagem oral e escrita é muito importante para a criança, desde sempre. O texto literário propõe que a criança explore os dois tipos de linguagem ao mesmo tempo. Por meio do texto literário a criança consegue fazer a identificação da imagem, assim já se apropria do texto escrito. Quando propomos para uma criança recontar a história por exemplo, mesmo sem saber ler, ela, olhando as figuras sabe das falas, dos personagens, onde está cada coisa, se apropriando assim da linguagem oral e da linguagem escrita. (Maria Clara, 15/04/20).
\end{abstract}

$\mathrm{O}$ ato de ler amplia as referências do pequeno leitor, desenvolvendo o pensar e o agir da criança. A leitura é também uma fonte de aprendizado, de lazer, de relação da criança com o mundo, para isso é preciso que ela avance para além da descoberta das primeiras palavras no papel. Porém a "identificação da imagem não é a apropriação do texto escrito, são dois processos diferentes, ler a imagem e ler o texto escrito.

Destaca Mello que, na Educação Infantil, não se trata de a criança aprender a ler e escrever como fim em si mesmos, isto é, descartando as funções e os usos da escrita, nem de alfabetizá-la precocemente, pois

[...] ler apenas para aprender a ler e escrever apenas para aprender a escrever configuram-se como fazeres que podem fazer sentido para o adulto que ensina, mas não para a criança que está sendo introduzida no mundo da escrita. (1999, p. 22).

No ato de ler, as crianças desenvolvem distintas habilidades, em diferentes linguagens e suportes de texto por meio das quais aumentam seu vocabulário, desenvolvem a imaginação, o pensamento, assimilando a cultura e dessa forma desenvolvendo suas capacidades, uma vez que, segundo Mello (1999), a aprendizagem permite à criança perceber sons, cores e formas, desenvolver suas funções psicológicas como o pensamento, a memória, a linguagem, de maneira a desenvolver a capacidade de ler, de escrever, de admirar o belo.

\title{
CONSIDERAÇÕES FINAIS
}

Buscamos, neste artigo, analisar a leitura literária em seus aspectos teóricos e práticos, por meio de narrativas da professora de crianças de 5 anos, de uma escola pública de 
Educação Infantil. O estudo abordou a leitura literária que mostra os processos de apropriação da cultura desde o nascimento do bebê, evidenciando a importância de a leitura entrar na vida da criança para abrir possibilidades dela se inserir no mundo, desenvolver-se, pensar e agir. A análise dos aspectos teóricos mostra que a leitura é uma fonte de aprendizagem, de prazer, e, sobretudo, de relação da criança com o mundo para sua constituição humana.

Ressaltamos que as questões teóricas mostraram a relevância quanto aos conhecimentos das habilidades desenvolvidas na infância pela criança, levadas para sua vida adulta, e por isso a necessidade de a criança cultivar uma relação com a leitura desde cedo. A leitura literária inserida no cotidiano da vida da criança, também, contribui para a formação do gosto literário. Nesse sentido, é papel da escola de Educação Infantil priorizar as atividades de linguagens, particularmente, da linguagem literária, e, em especial, do livro literário infantil como objeto cultural que carrega em si as formas mais elaboradas da cultura humana, a escrita.

Por meio da narrativa como instrumento de pesquisa foi possível conhecermos as concepções, os valores e as atitudes da professora que guiam suas práticas, seus conhecimentos e saberes empíricos sobre a temática leitura literária, ainda que de forma limitada pelo tempo e pelo distanciamento devido ao isolamento social provocado pela pandemia do coronavírus. A escolha da narrativa escrita intencionou também dar voz e vez à professora pelo papel fundamental que exerce na educação das crianças pequenas.

Apontamos algumas questões que dificultam o trabalho pedagógico com a leitura literária. A primeira delas é a adoção de livro didático cujo foco é a figura do professor, e, nesse contexto, a criança ocupa uma função de receptora dos conteúdos didáticos. A segunda questão é a contação de histórias em vez de leitura de histórias, pois a contação se caracteriza pelas marcas linguísticas de oralidade, enquanto que a leitura se assenta nas qualidades estéticas do texto escrito do gênero literário. A terceira questão é a abordagem do texto literário como pretexto para trabalhar ensinamentos, como nas situações em que a professor recorre ao texto literário para ensinar bons e maus comportamentos. E, finalmente, a quarta questão são os critérios estabelecidos para escolha do livro literário que não ficam claros, levando-se em consideração a esteticidade do texto literário e a qualidade do projeto gráfico do livro a se oferecer à criança.

Por outro lado, outros aspectos ressaltam situações que fortalecem a leitura literária. Um deles é a visita das crianças à biblioteca onde está sendo organizado um ambiente acolhedor para a leitura das crianças. Ressaltamos que a professora Maria Clara diversifica as leituras literárias no cotidiano escolar, embora em algumas situações não explore seu caráter estético. 
Isto posto, a análise dos dados evidenciou certo distanciamento entre os aspectos teóricos que dão sustentação a exploração da leitura literária e as práticas pedagógicas da professora. Nessa direção, entendemos que se faz necessária a organização das condições para as experiências das crianças com os livros e a leitura literária, o que aponta para a importância da formação teórico-metodológica da professora.

Enfim, enfatizamos a relevância das práticas de leitura literária na escola de Educação Infantil que assegurem o mergulho das crianças na cultura escrita, em atividades que façam sentido para elas, e que contribuam para seu desenvolvimento.

\section{Referências}

BAJARD, E. Óculos de leitura: Escuta do texto ou leitura? Na Ponta do Lápis, v. VI, n. 13, fev. 2010.

BATISTA, M. C. S. Práticas cotidianas na educação infantil: bases para a reflexão sobre as orientações curriculares. Brasília: MEC, Secretaria da Educação Básica, Universidade do Rio Grande do Sul, 2009.

BARBOSA, M. C. S. Práticas cotidianas na Educação Infantil: Bases para a reflexão sobre as orientações curriculares. Brasília: MEC, SEB, 2009.

BORTOLANZA, A. M. E. O texto sedutor na literatura: apontamentos para uma leitura da literatura infantil brasileira contemporânea. Álabe, nº 4, dez. 2011.

BORTOLANZA, A. M.; FREIRE, R. T. J. Educação Literária e formação de leitores na escola. In: MARTINS, R. A. F. Literatura e vida social. Jundiaí: Paco Editorial, 2018.

BRASIL. Ministério da Educação e da Cultura, Conselho Nacional de Educação, Câmara da Educação Básica. Introdução das Diretrizes Curriculares Nacionais para Educação Infantil. Brasília, 2010.

BRASIL. Ministério da Educação, Secretaria de Educação Básica, Fundo Nacional de Desenvolvimento da Educação. PNLD 2019: Educação Infantil - guia de livros didáticos. Brasília, DF: Secretária de Educação Básica, 2018.

CARVALHO. M. I. C.; RUBIANO. M. R. B. Organização do espaço em instituições préescolares. In: OLIVEIRA. Zilma de Morais Ramos de (org.). Educação infantil: muitos olhares. São Paulo: Cortez. 2000.

COLOMBO, F. J. A literatura infantil como meio para a formação da criança leitora. Dissertação (Mestrado em Educação) - Faculdade de Filosofia e Ciências, Universidade Estadual Paulista, 2009.

FINO, C. N. Vigotski e a zona de desenvolvimento proximal (ZPD): três implicações pedagógicas. Revista Portuguesa de Educação. Braga, (Portugal), v. 14, n.2, p. 273- 291, 2001. Disponível em: http://www3.uma.pt/carlosfino/publicacoes/11.pdf. Acesso: 20 dez. 2011. 
FIORENTINI, D.; CRECCI, V. Desenvolvimento profissional docente: Um termo guardachuva ou um novo sentido à formação? Formação Docente. Belo Horizonte, v. 05, n.08, p. 11-23, jan/jun.2013.

FURTADO, C. C.; OLIVEIRA, L. BIBLON: plataforma de incentivo à leitura para crianças. Revista da Ciência, Informação e Documentação. Ribeirão Preto, v. 2, n. 1, jan/jun. p. 68-85, 2011.

JUNQUEIRA, A. M. R. A constituição autora e leitora de crianças de três anos de idade. 2015. Dissertação (Mestrado em Educação) - Universidade de Uberaba, 2015.

LIMA, M. E. C. de C.; GERALDI, C. M. G.; GERALDI, J. W. O trabalho com narrativas na investigação em educação. Educação em Revista. 2015, vol.31, n.1, pp.17-44. Disponível em: <http://dx.doi.org/10.1590/0102-4698130280>. Acesso em: 9 de abril. 2017.

MELLO, S. A. Algumas Implicações Pedagógicas da Escola de Vygotsky para a educação Infantil. Pro-posições. Campinas, v. 10, n.1, 1999, p. 16-27.

MINAYO, M. C. S. (org.). Ciência, técnica e arte: o desafio da pesquisa social. In: MINAYO, M. C. de S.; DESLANDES, S. F.; GOMES, R. Pesquisa social: teoria, método e criatividade. Petrópolis: Vozes, 1993.

RAMOS, F. B.; PANOZZO, N. S. Modalidades narrativas: cantos lusitanos em quadrinhos. In: RAMOS, F. B.; PANOZZO, N. S. P. Mergulhos de leitura: a compreensão leitora da literatura infantil. Caxias do Sul, RS: Educs, 2015.

RIBEIRO, A. E. M. Literatura infantil e desenvolvimento da imaginação: trabalho modelado como ferramenta de ensino do argumento narrativo. 2018. Tese (Doutorado em Educação Brasileira). Faculdade de Filosofia e Ciências, Unesp, Marília, 2018.

RODRIGUES, M. C.; BORTOLANZA, A. M. E. Contradições entre linguagem escrita e código alfabético: $\mathrm{O}$ que revelam professoras sobre a apropriação da escrita pelas crianças na educação infantil. Dialogia. São Paulo, n. 31, p. 111-119, jan./abr. 2019.

SILVA, M. Usos da literatura na Educação Infantil: um percurso entre o pedagógico e o estético. In: BAPTISTA, A. M. H.; NAVAS, D.; HUMMES, J. M.; DAL BELLO, M. P. (Orgs.). Educação \& O Belo e o Sublime. São Paulo: BT Acadêmica, 2017.

Artigo recebido em: 07/12/2020. Artigo aceito em: 23/01/2021. 